\title{
Article
}

\section{The Tales of Alphanumerical Symbols in Media: The Case of Bitcoin}

\author{
Jonas Hedman $^{1, *}$, Tanya Beaulieu ${ }^{2}$ and Michael Karlström ${ }^{1}$ \\ 1 Department of Digitalization, Copenhagen Business School, Howitzvej 60, 2000 Frederiksberg, Denmark; \\ michael.a.karlstrom@gmail.com \\ 2 Maine Business School, University of Maine, Orono, ME 04469, USA; tanya.beaulieu@maine.edu \\ * Correspondence: jhe.digi@cbs.dk
}

Citation: Hedman, J.; Beaulieu, T.;

Karlström, M. The Tales of

Alphanumerical Symbols in Media: The Case of Bitcoin. J. Theor. Appl. Electron. Commer. Res. 2021, 16, 2768-2792. https://doi.org/10.3390/ jtaer16070152

Academic Editor: Steve Worthington

Received: 2 August 2021

Accepted: 11 October 2021

Published: 14 October 2021

Publisher's Note: MDPI stays neutral with regard to jurisdictional claims in published maps and institutional affiliations.

Copyright: (c) 2021 by the authors. Licensee MDPI, Basel, Switzerland. This article is an open access article distributed under the terms and conditions of the Creative Commons Attribution (CC BY) license (https:// creativecommons.org/licenses/by/ $4.0 /)$.

\begin{abstract}
Bitcoin, a decentralized cryptocurrency, has not only given rise to a wave of digital innovations but also stirred up considerable controversy. Some have hailed it as the most significant innovation since the Internet, while others have dismissed it as a Ponzi scheme that should be abandoned and forbidden. Regardless of these varying views, this is an innovation in need of scrutiny. In this paper we present a metastory of Bitcoin, based on an interpretative study of 737 news articles between 2011-2019. Through our analysis, we identified five narratives, including The Dark Side, The Bright Side, The Tulip Mania, The Idea, and The Normality. Our analysis demonstrates the interpretive flexibility of technology as influenced by ideologies, and we construct a theoretical model demonstrating media's role as constructor and conduit. The metastory provides an institutional look at the broader interpretations of digital innovations as well as the multifaceted nature of digital innovations and how their interpretation evolve over time.
\end{abstract}

Keywords: Bitcoin; digital innovation; constructionist; narrative analysis; qualitative; news media

\section{Introduction}

On 31 October 2008, a digital innovation was born, conceived by Satoshi Nakamoto's white paper "Bitcoin: A Peer-to-Peer Electronic Cash System" [1]. It marks the starting point of a storied tale of an emerging monetary and payment innovation that has stirred up considerable controversy. The Bank of England has portrayed Bitcoin and its underlying technology as a "first attempt at an Internet of finance", the Federal Reserve Bank of St. Louis referred to it as a "stroke of genius", and the World Economic Forum stated that "the blockchain protocol threatens to disintermediate almost every process in financial services" [2]. Meanwhile, there are critics as well. The former Federal Reserve Chairman Alan Greenspan has called it a "bubble without intrinsic value" [3], and the economist Nouriel Roubini declared Bitcoins a "Ponzi scheme" and a "lousy" store of value [4]. But the strongest criticism comes from the Nobel Prize-winning economist Joseph Stiglitz who argued that "Bitcoin is successful only because of its potential for circumvention, lack of oversight" and "it ought to be outlawed". Evidence of both positive and critical interpretations express the tension and conflicting nature in digital innovation as communities and society grapple with its use and meaning.

News media plays an essential role in driving risk and returns [5], and making sense of digital innovations [6], especially at the point when a new phenomenon emerges [7] due to the existence of multiple frames through which novel innovations may be viewed [8]. Through these frames, news media influences and shapes the public debate [9]. Individuals and organizations-like Alan Greenspan and the Federal Reserve Bank of St. Louis—utilize news media in their sensemaking process [10]. The content or communicative event is either aligned or not with the stakeholder's individual 'schemas' and 'scripts' that are employed to make sense of reality [11,12], but are important in understanding how digital innovations are understood [10] and ultimately adopted and diffused in society [13]. Articles, like the first publication on Bitcoin in 2011 by Time Magazine, describes it as a "revolutionary 
concept". In describing it as such, Time Magazine clearly provided a specific framing of Bitcoin, which may fit or conflict with existing interpretations applied by other stakeholders. It is through the interaction of alternate frames that stakeholders' understandings and actions adapt over time in the sensemaking process.

Following the media attention and technology diffusion, researchers begin to explore the phenomenon. The current research on the Bitcoin evolution is promising by its breadth and depth $[14,15]$. We find a broad diversity of research topics including technical aspects, such as securing anonymity [16,17], blockchain [18], mining [19], and cryptography [20]; financial issues, such as risks and governance [21], unbanked people [22], currencies [23,24], investment [25], financial inclusion [26]), financial instrument [27], and payment system [21,28-30]; criminal activities [31]; regulation [32], trust and privacy [32-34]; ideology [35]; political issues [36]; user behavior [37]; and market efficiency [38,39].

From our review of the literature, we observe that researchers often approach Bitcoin from an inside-out perspective and consequently miss covering the broader context that shapes actors' framing of the phenomena. This is a common limitation in technology innovation research [13]. Where researchers tend to attend to the hype of the technology (see for instance [40]), thereby missing the institutional context in which the phenomenon emerges. Swanson and Ramiller [13] (pp. 458-459) highlight this when criticizing technology innovation research for assuming that "early adoption of innovations is based on local, rational organizational choice, while later adoption is institutionalized and follows taken-for-granted assumptions about what constitutes proper practice". This assumption has prompted scholars to call for a more 'institutional' understanding of the phenomenon that leads to the diffusion of digital innovations $[8,10,13,41]$. Therefore, building and extending on past tradition, we aim to understand the nature and the institutional context surrounding digital innovations that media influence and what type of stories media create and how they reinforce and changes the narrative of digital innovation. To this end, our research objective is to understand the interweaving of news media narratives, events, and exchange rates to reveal a meta story of the digital innovation of Bitcoin.

Drawing upon a constructionist philosophy [42], this paper reveals a meta story of Bitcoin as told through two major news outlets from Sweden and the USA. Our goal, through this research, is to reveal the intertwining evolution of media and technology sensemaking. Through the analysis of 737 news articles, we develop a theoretical model showing how media construct Bitcoin and thereby provide an institutional look at the broader context of digital innovations. Our narrative approach $[43,44]$ focuses on the involved actors and the telling of events related to the emergence and evolution of the Bitcoin. The narratives are a step towards theorizing of digital innovations and contribute to our understanding of "what is, how it has come to be, and what it might become" [45]. We identify five narratives, including The Dark Side, The Bright Side, the Tulip Mania, The Idea, and The Normality, and then follow these narratives over time as they tell the unfolding story of the Bitcoin. The narratives demonstrate different frames used in the interpretation of digital innovations.

The remainder of the paper is structured as follows. In the next section, we introduce our theoretical and methodological backdrop for the study. In Section 3, we discuss our methodological choices and analytical approach in detail. Thereafter, the findings are presented, followed by a discussion of the study's implications and limitations and future research. To conclude, final insights and highlights of the paper are presented.

\section{Theoretical Framework}

Narratives are written or spoken stories told to describe or explain an event, a process, or a phenomenon over time [46]. Stories contain two dimensions-there is the set of actions that take place, the agents, and the instruments which together constitute the "story grammar", while the other dimension is one of "consciousness" or how the story affects what one "knows, thinks, or feels" [47] (p. 14). Analyzing narratives involves taking constructed accounts, deconstructing them, and then reconstructing them to reveal insights 
not otherwise available [48]. The result is that a narrative inquiry captures a story and provides an "analytic examination of the underlying insights and assumptions that the story illustrates" [48] (p. 7).

The outcome or result of a narrative inquiry is a "meta story" of what has occurred by editing, interpreting, and drawing inferences from the individual stories told [44]. The strength of a narrative approach is a holistic view that takes into account the roles played by the technical artifact and the actor within the story [43] and proven especially effective at understanding sensemaking [49]. Narrative inquiry helps us understand what an innovation means within the context of a given point in time. This is not an objective process, nor is meaning "subjectively constructed", instead, the meaning is created by observing and interpreting the interactions and entanglement of actors and artifacts over time [50] (p. 159). Whereas a logico-scientific approach provides generalized, concise, black-box theories, narrative inquiries are interpretive [51] and reflect more on how people actually think [52]. Narratives open this black-box to "keep the conversation and controversy alive" [53]. This is especially valuable in studying technology as a means to analyze the interconnectivity of events over time and from different perspectives [54,55], to reveal a diversity of views towards technology diffusion, where each aspect may not necessarily compete for dominance but instead disclose the disparate views of varying actors [56,57]. Thus, narrative inquiries enable unique insights into an emerging phenomenon where perceptions are still forming and where the media can be particularly influential [55].

From a theoretical perspective, narrative studies have become increasingly popular and have been applied in a wide array of academic domains, including the study of technology and innovation. Narratives have been shown in the knowledge management domain to be effective in transferring tacit organizational knowledge [58,59]. Narratives utilizing a storytelling approach have been successful in studying organizational issues such as the influence of culture. For example, Dubé and Robey [60] used organizational stories to identify cultural aspects of managing software development, and Alvarez and Urla [61] found that users' telling hypothetical and personal narratives proved to be a valuable method for gathering requirements. Stories are also valuable in relationship building across cross-cultural situations, such as those found within outsourcing [62], as well as how technology use evolves [56]. To this end, narrative studies have the power to provide novel insights, especially when examining new phenomena.

\section{Method}

Given a constructionist philosophy [42,63,64], we used an interpretive approach [65] to support our narrative analysis [43]. Ontologically, we take the stance that while phenomenon and events have "material properties and consist of real action", we ascribe to the notion that "socially constructed reality consists of social meaning that cannot be defined objectively or precisely" [60] (p. 299). The validity of an interpretive study is not gained in a statistical sense but instead through discussion and consensus as advocated by Morse [66] and Saldaña [67] and as exemplified by Berente and Hansen [68] and Edberg, Ivanova, and Kuechler [69]. Walsham [70] cautions interpretive researchers against "careless work", and to that end, we followed the seven principles of Klein and Myers [65] to conduct our research:

Principle 1: The Fundamental Principle of the Hermeneutic Circle. Through our review of the news articles, our analysis was not linear in a singular direction to final insights. Instead, as suggested by Principle 1, our interpretations were sometimes met with inconsistencies which by circling back to previous interpretations and realigning our insights, we were able to bring all the pieces at the coding level as well as meta level together into a whole.

Principle 2: The Principle of Contextualization. We followed this by setting our research in the institutional context, which accounted for not only current events surround and related to Bitcoin but also a historical context. For example, the economic downturn of 2008 left indelible marks not only on economies, but psyche's as well. It was this 
context that inspired a Libertarian open code which represented calls to abandon central government authority.

Principle 3: The Principle of Interaction between the Researchers and the Subjects. As this principle is concerned with working together with human subjects-it is not applicable to the present study.

Principle 4: The Principle of Abstraction and Generalization. The concept of generalization from qualitative studies is often misunderstood as it may be confused with statistical generalizations. The goal in an interpretive study is to move toward analytic generalizations [71,72]. We accomplished this through our data analysis which sought to understand the phenomenon at hand as well as tie our insights into broader theoretical concepts.

Principle 5: The Principle of Dialogical Reasoning. Interpretive studies welcome conflicts between their preconceptions and actual data as that is where the story lies, and the insights can be made. As a research team we embraced our preconceptions and biases by being open to explore our biases and discover "true prejudices", leading to deeper understanding [72].

Principle 6: The Principle of Multiple Interpretations. Aligning well with principle 1 , it is critical that the researcher not stop at one interpretation but instead should recognize the likelihood of multiply ways of explaining, "similar to multiple witness accounts even if all tell it as they saw it" [65]. We addressed this issue through multiple interactions between the data, our ideas, and group discussions whereby possible explanations or storylines were vetted by the team and against the data.

Principle 7: The Principle of Suspicion. This principle "requires sensitivity to possible 'biases' and systematic 'distortions' in the narratives collected from the participants". And while we did not collect interview data, it is important to recognize and address personal biases within the research team. For example, one bias inherent in a multinational research team is our personal biases toward our country and our media representation. The members of the research team were well educated and financially stable, thus potentially biasing our view of Bitcoin as primarily a store of wealth, a societal statement, etc. These biases, while perhaps not changed as the result of this research, were recognized, and became part of our analysis.

Through our interpretive approach, the aim is not to construct an objective reality but instead to better understand how the narratives put forth by media lead to meaning and actions [42]. Through the identification of events, media content, and frames, our goal is to present a meta story that connects micro-events to "broader discourses as a way to show how narratives construct the social experience" [73] (p. 9). In the next sections, we describe in detail how data was collected and analyzed.

\subsection{Data Collection}

Our data consists of news articles from two influential and leading newspapers from Sweden and the United States: Svenska Dagbladet (SvD) and The Washington Post (WP), respectively. These media outlets were selected as they are both mainstream daily newspapers that are held in high regard from two countries that are well known in terms of digital innovations. As opposed to trade journals and outlets that focus on technical issues (e.g., Computer World, Wired, etc.), we sought media with broad coverage and perspectives to fit within our research objective.

We identified news articles published between 2011 and 2019 by searching the newspapers' websites for the term "Bitcoin" across all content, including editorials, news articles, blogs, etc. We conducted the search across three time periods, 2016, 2017, and 2019, and identified 416 news articles in Svenska Dagbladet and 334 news articles in Washington Post. After removing 13 duplicate articles, our corpus included 737 news articles that were assigned a unique identifier. Figure 1 represents an overview of our iterative process, from data collection to data analysis, followed by a description of each step below. 


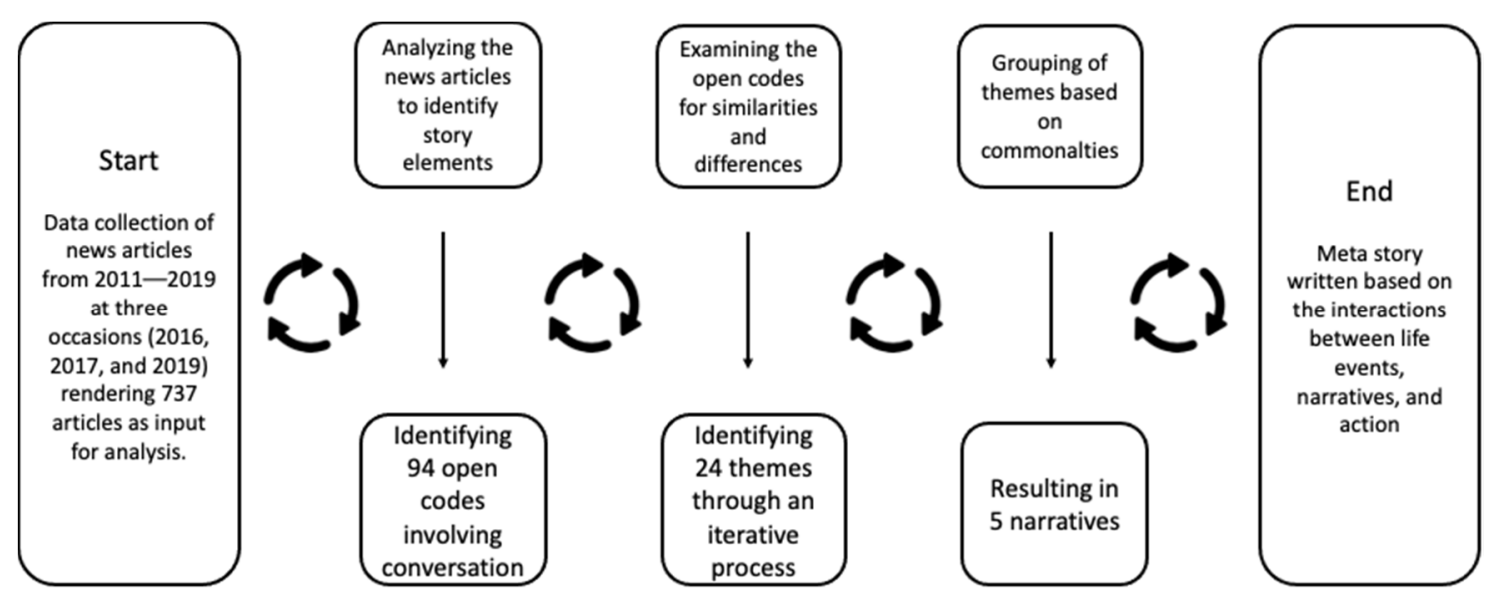

Figure 1. Process of Data Collection, Coding, and Subsequent Analysis.

\subsection{Data Analysis}

From our analysis emerged a coding scheme used to group, regroup, and categorize in order to link concepts and constructs within the data as a way of eliciting meaning [67]. Our data, consisting of persistent text, provides the benefit of being able to see ahead and see behind to gain insights. This allowed the analysis to capture not only an interpretation based on the understanding at that time but also to reinterpret over time, allowing the text to speak for itself [74]. Thus, our approach is hermeneutic in spirit, where interpretations are tried, retried, and validated as the story unfolds [75].

\subsection{Open Coding}

In the first step of our analysis (open coding), the articles were carefully read in order to identify framing and story elements such as actors, actions, and events [63]. Additionally, the main topics, as well as any historical context that might place the content within perspective, were noted. Each article was treated as a communicative unit that carried a certain attitude and interpretation of the actions and events unfolding. It was critical during this first step to let codes emerge naturally from the data without implying theoretical constraints. We allowed multiple codes to be assigned to one article when an article pertained to several open codes.

The research team was comprised of three researchers; two researchers were fluent in Swedish, and all three authors were fluent in English. The SVD articles were coded by the two Swedish speakers, and all three authors participated in coding the WP articles written in English. The first author participated in all the coding work, while the third author participated mainly in the early coding of the articles, while the second author participated mainly in the later coding of the articles. In addition to discussions amongst the research team, the non-Swedish speaker at times used Google Translate to review and clarify their understanding.

The coding of articles was accomplished a "handful" at a time with frequent conversations between the research team members to ensure consistency and to develop a common ground of understanding [76]. Initially, two authors coded each article individually with comparison coding, where differences were discussed by the research team and resolved. After the open codes began to solidify, articles were coded by a single researcher, with meetings to consolidate and discuss findings. The discussions generally revolved around coding uncertainties, and/or when a new open code was proposed, all researchers met to agree to the new code. This process at times would then ripple into previously coded articles which were re-coded to align with new understandings. The approach was iterative with a focus on possibilities of meaning instead of tracking inter-rater reliability scores. The value of qualitative research increases when taken-for-granted assumptions and biases of individual researchers are brought into question and discussed through clarifications, offering alternative thinking, and even playing "devil's advocate" at times. Thus, our goal 
in the coding was less content analysis (where inter-rater reliability scores toward concrete constructs is desired) and more toward gaining a deep sense of the phenomenon being studied [77]. In this way, an agreed meaning emerged inductively through the process. Through this process, 94 open codes were identified, see Appendix A for a complete list.

\subsection{Themes Identification}

In the next step, the open codes were examined for similarities and differences with each other leading to the emergence of initial themes [67]. This was accomplished by constructing themes that held internal consistency, and that also maintained distinctiveness from other themes. While this was accomplished in many instances based on topic (e.g., open codes related to different aspects of risk were consolidated), other means of grouping were also used. For example, the open codes of Acceptance and Merchant Adoption were consolidated into a theme of Adoption given that both play key roles in the Bitcoin environment as the users of bitcoin (i.e., buyers), and adoption of bitcoin by merchants (i.e., sellers). As during the open coding step, the identification of themes was derived by the research team. The process was iterative and involved constant comparison [78] between emerging themes, open codes, and the underlying data with reflection and discussion between the research team members in order to provide an inextricable link between the content in the articles and the themes. As themes were proposed, the associated open codes and underlying articles were reviewed to validate the appropriateness of the theme, and adjustments were made as necessary. From this process, the themes emerged. While each open code was assigned to one theme, because an article may have been assigned multiple open codes, an article may be counted under more than one theme.

\subsection{Narratives Identification}

The themes were thematically grouped, based on commonalities, into what became five narratives. For example, the themes "illegal activity", which includes stories of how Bitcoin can be used by criminals, and "security", which deals with threats by hackers on the Bitcoin community was associated with a single narrative. Separately, individual themes primarily convey information about the content, but when they are grouped, we can more clearly see how these communicative events take part in the construction of social reality. Identifying the narratives allows us to identify "predictable and patterned ways" [79] (p. 331) of framing images of reality, which is how mass media constructs social reality and thereby gains a significant impact on society. Extant research was also consulted to support the emergence of the narratives. The 24 themes led to five narratives: The Dark Side (related to criminal activities), The Bright Side (related to innovation), The Tulip Mania (related to the volatility and speculation), The Idea (related to the foundation of Bitcoin), and The Normality (related to how Bitcoin becomes part of the everyday life). The results of our analysis, including the identified themes, narratives, and exemplar articles, may be found in Table 1.

Table 1. Emergent Narratives and Associated Themes.

\begin{tabular}{cc}
\hline Narrative & Theme \\
\hline The Bright Side & Adoption \\
\hline Example: Bitcoin's positive reception from policymakers was just one sign that the cryptocurrency is becoming increasingly mainstream. \\
$\begin{array}{c}\text { On Thursday, the largest private university in Cyprus, the University of Nicosia, announced it would allow tuition to be paid with bitcoins. } \\
\text { Richard Branson's Virgin Galactic said Friday that it would accept Bitcoin payments for space travel. And the Bitcoin start-up Bitpay says } \\
\text { that 12,000 merchants have signed up to receive payments through its service. }\end{array}$ \\
http://www.washingtonpost.com/business/economy/for-bitcoin-a-successful-charm-offensive-on-the-hill/2013/11/22/000 \\
ed4b0-53b1-11e3-a7f0-b790929232e1_story.html (accessed on 5 October 2021) \\
The Bright Side & Alternate Currencies
\end{tabular}


Table 1. Cont.

\section{Narrative}

Theme

Example: ... while the price of bitcoin is determined by market demand, leading to enormous volatility, Libra is backed by a financial reserve that mixes the world's major stable currencies. That stability, he said, should offer the currency utility for consumers rather than a gamble for investors.

https:/ /www.washingtonpost.com/technology/2019/06/18/with-calibra-facebook-launches-cryptocurrency-network/ (accessed on 5 October 2021)

The Bright Side Bitcoin Ecosystem

Example: The company was founded in 2013 and began its path of developing and selling computers to extract Bitcoin, but during the past year they have increasingly turned to renting out computing capacity. To this end, a very extensive data center facility has been built in Boden, where the company's own developed computers fill gigantic server rooms.

http:/ / www.svd.se/svenska-startupbolag-toppar-wall-street-journal-lista (accessed on 5 October 2021)
The Bright Side
Entrepreneurship

Example: If you want to do an initial coin offering you first come up with a business plan and then you issue tokens. The tokens are like shares. The investors who buy your tokens hope that your company's plan succeeds so that the value of your tokens grow. That's what the investors of Bancor, who include noted venture capitalist Tim Draper of Draper Fisher Jurvetson, are hoping for.

https:/ / www.washingtonpost.com/news/on-small-business/wp/2017/06/15/the-crazy-new-way-this-start-up-raised-153million-in-just-three-hours / (accessed on 5 October 2021)

The Bright Side Financial Disruption

Example: Are the banks doomed? Yes, at least if you have to rely on surveys that show that more than two-thirds of young people would rather go to the dentist than to their bank. Furthermore, they are convinced that new payment services will come in the long term. In a new survey, US youths are violently attacking traditional banks, which close offices, pay 0.1 percent in savings and stop handling cash. 33 percent do not think they need a bank at all in the long run.

https: / / www.svd.se/droger-kan-bli-ny-natvalutas-fall (accessed on 5 October 2021)
The Bright Side
Innovation

Example: The important thing is not how the value goes up and down, but the technology, he [Christoffer De Geer, vice president of the BTCX trading site] says in Economics.

https:/ / www.svd.se/bitcoin-ar-en-revolution-som-ar-har-for-att-stanna (accessed on 5 October 2021)
The Bright Side
Investment

Example: Bitcoin enthusiasts prepare to reach a new landmark. On Sunday, a bitcoin product will trade for the first time on a U.S. financial market, making it almost as easy to bet on the virtual currency as oil, corn or the euro.

https: / / www.washingtonpost.com/business / economy/bitcoin-soars-above-17000-boosting-worries-and-a-worldwide-frenzy/ 2017/12/07/439e71e8-db68-11e7-b1a8-62589434a581_story.html (accessed on 5 October 2021)
The Bright Side
Mechanics

Example: Who's in charge of it? No one. Or, rather, everyone who uses it. Bitcoin functions on a peer-to-peer computer network based on cryptography rather than a trusted third party. It is an open-source and self-governing system. A software code maintains a public ledger that records and verifies each transaction without revealing the identity of the users. Users who provide hardware and bandwidth for these

transactions are rewarded by the algorithm with new denominations of bitcoin to save or sell into circulation. This process of earning new bitcoin is called "mining."

https:/ / www.washingtonpost.com/lifestyle/style/what-is-bitcoin-anyway /2014/01/23/599bf8de-83a2-11e3-9dd4-e7278db8 0d86_story.html (accessed on 5 October 2021)

The Bright Side Political

Example: The digital, decentralized currency bitcoin has undergone an explosive increase in value in recent weeks. This is the result of a growing distrust of debt-ridden states in general and of euro area countries in particular. If European deficit policy does not end, more and more people will turn to currencies that politicians cannot control or tax.

https: / / www.svd.se/bitcoin-valutans-framfart-ar-ett-misslyckande-for-euron (accessed on 5 October 2021)

\section{The Bright Side}

Production

Example: Deep inside the mountain is one of Sweden's few "bitcoin mines". The history of the digital currency is bordered by modern gold diggers, cyber punks, drug dealing, sensational value increases and deep races. I took every penny I had and invested in the "mining", says Linus Dunkers, who runs the mine.

https:/ / www.svd.se/han-skapade-hajpade-bitcoin-valutan---i-egen-gruva (accessed on 5 October 2021) 
Table 1. Cont.

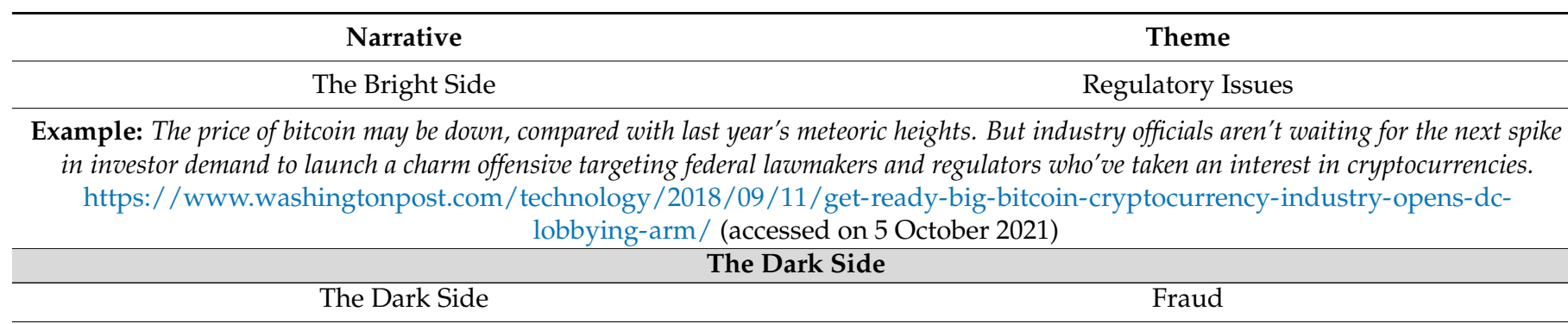

Example: As it turned out, only I knew the passwords to the digital wallets where cryptocurrency was stored, meaning that more than 100,000 users were unable to access at least \$145 million in assets, according to Bloomberg News. As months passed and the money failed to materialize, a conspiracy theory emeICotten had faked his own death and disappeared.

https:/ / www.washingtonpost.com/nation/2019/1Ierald-cotten-quadrigacx-cryptocurrency-death-body-exhumed/ (accessed on 5 October 2021)

The Dark Side Illegal Activity

Example: The original Silk Road, part of what's known as the Dark Web because it's not easily accessible to all Internet users, was notorious for offering drugs, weapons and other illicit goods for anonymous sales, with transactions made in bitcoins, an online currency that's more difficult for authorities to trace than traditional currencies issued by governments. The FBI arrested the founder of the original Silk Road, Ross William Ulbricht, in October 2013 and seized the site's assets, including bitcoins valued at \$33.6 million. He allegedly went by the alias "Dread Pirate Roberts".

https:/ / www.washingtonpost.com/business/economy/silk-road-20-web-site-leads-to-arrest-charges/2014/11/06/883eb7e0-6 604-11e4-9fdc-d43b053ecb4d_story.html (accessed on 5 October 2021)
The Dark Side
Risk

Example: Risky to trade bitcoin on credit-but legally in Sweden American banks say no-Swedish says yes. Credit purchases of crypto currencies should not be prohibited, believes Nordea, SEB, Handelsbanken and Swedbank. At the same time, they warn of the risks. https:/ / www.svd.se/ riskfyllt-att-handla---itcoin-pa-kredit--men-lagligt-i-sverige (accessed on 5 October 2021)

The Dark Side Security

Example: Losses at Mt. Gox have been put at more than $\$ 400$ million, and experts say it's not clear whether that money was stolen by criminals or somehow mishandled by the operators of the exchange. Company officials have blamed a glitch in the transaction software that, they say, allowed hackers to siphon away money undetected.

https:/ / www.washingtonpost.com/business/technology/mt-gox-collapse-spurs-calls-to-regulate-bitcoin/2014/02/28/df44f5 c6-a0b7-11e3-a050-dc3322a94fa7_story.html (accessed on 5 October 2021)
The Dark Side
War/Terrorism

Example: Cryptocurrency has come to terrorism, with an array of terrorist organizations exploiting the anonymity afforded by blockchain technology for fundraising and finances, yet U.S. counterterrorism officials appear to have been slow to grasp the extent the problem. https:

/ /www.google.com/search?client=firefox-b-1-d\&q=washington+post+The+cryptocurrency-terrorism+connection+is+too+big+ to+ignore $\% 3 \mathrm{~A}+\mathrm{An}+$ emerging+cadre+of+terrorist+groups+are+turning+to+encrypted+messaging+and+cryptocurrencies (accessed on 5 October 2021)

\section{The Idea} The Idea

Example: But the city is overflowing with ever more new temples to youthful exuberance, liberation and counterculture. Seedy watering holes that let you pay for your beers in Bitcoin. Urban communes promising life "without bosses" or "nuclear families."

http:/ / www.washingtonpost.com/world/europe/in-berlin---ife-is-a-cabaret--again/2014/11/06/fe033738-5f76-11e4-827b-2d8 13561bdfd_story.html (accessed on 5 October 2021)
The Idea
Satoshi

Example: In his initial writings about Bitcoin, Nakamoto claimed to be a 36-year-old from Japan who had been driven by anger about the 2008

financial crisis to try and invent an alternative. But many Nakamoto-hunters believe their man (or woman) is a native English speaker: the person who blogged about Bitcoin extensively before signing off in 2011 wrote in flawless English and tended to use British spellings-"colour", "grey" - once described something as "bloody hard" and embedded a reference to the Times of London into the "genesis" lines of code that got the currency started, according to the New Yorker.

https:/ / www.washingtonpost.com/news/morning-mix/wp/2015/12/10/the-long-perplexing-search-for-the-creator-ofbitcoin-just-took-another-weird-turn/ (accessed on 5 October 2021) 
Table 1. Cont.

\begin{tabular}{ccc}
\hline Narrative & Theme \\
\hline Normality & Normality & \\
\hline & & Subordinate clause \\
\hline
\end{tabular}

Example: Textual sleuths find clues not in fingerprints or handwriting, but in word choice, spelling, punctuation, character sequences and in

subtle (and usually subconscious) patterns of sentence structure. The sleuths have sprung into sight in recent years with such pop-culture

stunts as identifying the author of "The Cuckoo's Calling" (J.K. Rowling) and joining last year's hunt for the bitcoin founder. But as language specialists enter the legal world, they find the stakes are high, the science uncertain and the scrutiny intense.

https:/ / www.washingtonpost.com/lifestyle/magazine/should-texts-e-mail-tweets-and-facebook-posts-the-be-newfingerprints-in-court/2015/02/19/a5ec2bf6-6f32-11e4-8808-afaa1e3a33ef_story.html (accessed on 5 October 2021)

Normality Legal

Example: This year, the Swedish Tax Agency will increase its efforts against cheating and controls of the digital economy will increase, including the trading of cryptocurrencies, says Henrik Kisterud, national coordinator at the Swedish Tax Agency for Economics. https:/ / www.svd.se/skatte---rket-mobiliserar--synar-bitcointillgangar (accessed on 5 October 2021)

Normality
Exampleyment
first major companies to pay wages in cryptocurrency. Up to the equivalent of 100,000 yen (just over SEK 7500) per person and month can be
obtained in bitcoin from February, GMO Internet announces.
https:/ / www.svd.se/japanska-anstallda-kan-fa-lon-i-bitcoin (accessed on 5 October 2021)

\begin{tabular}{ccc}
\hline Normality Total & & \\
\hline & Tulip Mania & \\
\hline Tulip Mania & & Bubble
\end{tabular}

Example: During Wednesday afternoon, the Bitcoin bubble seems to have finally burst. From the $\$ 260$ high of Bitcoin, the value plummeted to a $\$ 130$ low in just six hours. At the time of writing, the value is $\$ 180$.

https: / / www.svd.se/bitcoin-bubblan-sprack (accessed on 5 October 2021)
Tulip Mania
Death Sentence

Example: A leading developer has sold all of his bitcoin and left the project after an infected battle. The message caused the crypto currency to collapse. Last year it was ranked as one of the world's's best performing currencies. Now, a leading developer behind Bitcoin says the cryptocurrency is close to a technical collapse.

https:/ / www.svd.se/bitcoin-nara-en-teknisk-kollaps (accessed on 5 October 2021)

Tulip Mania Volatility

Example: Consider its volatility. Rotunda points out that a bitcoin was valued at less than \$14 in January 2013 and jumped to \$1200 in November 2013. Most recently it dropped to about $\$ 400$ after the news about Mt. Gox. "My biggest concern about Bitcoin is that it's trendy and there's a lot of buzz about it", he said in an interview. "But you can't get caught up in the buzz and trendiness of it and lose sight of the inherent risk. This is the type of risk that can wipe out someone's retirement account in a matter of minutes. That's the flip side of this coin".

https:/ / www.washingtonpost.com/business/investing-in-bitcoin-has-a-dangerous-flip-side/2014/02/28/09af7f54-9e5e-11e3-9 ba6-800d1192d08b_story.html (accessed on 5 October 2021)

\subsection{Meta Story}

As the analysis was taking place, the media articles and resulting themes and narratives were compared against the global context surrounding events related to Bitcoins. A central notion of narrative inquiries is that social practices are tied to specific historical contexts and serve as a way of reproducing or challenging existing social relations [80]. Therefore, as Hardy [81] points out, we must also understand the cognitive, social, and political contexts in which they arise. Building on the fact that narratives are not produced without context, we contextualize the emerging narratives against a backdrop of significant events that are related to the world of Bitcoin, as well as the exchange rate of Bitcoin. Following Langley's [82] process theory approach, our meta story is constructed from the analyzed data using time as anchor points. In creating the Bitcoin meta story, we drew upon the analyzed articles, actual events (such as the emergence of BitcoinXT), as well as historical postings found on sites such as coin.co/Bitcoin-guide/history, historyofBitcoin.org, and the English Wikipedia site (search term: "History of Bitcoin"). The events were assessed based on their magnitude, newsworthiness, and implication for the greater 
social context. This allowed us to triangulate our core data and analysis with other sources. By studying how the discursive practice has changed over time, a significant groundwork is laid that will support a discussion on how the texts are positioned, why that is, and what the consequences are.

\section{Findings}

Bitcoin is a fascinating digital innovation. From an objective reality perspective, a Bitcoin is nothing more than a string of alphanumerical symbols, for example, "1Ez69SnzzmePmZX3WpEzMKTrcBF2gpNQ55". This is a classic example, representing the 30.000 Bitcoins that were sold by the U.S. government on 1 July 2014, after the Silk Road bust [83]. While its long-term impact on society is still uncertain, what we find is that the phenomenon has attracted attention for almost a decade. Additionally, we found that the media coverage included a variety of aspects or frames ranging from having the potential of disrupting finance and payment, creating new fortunes, to being a tool for criminals.

In Figure 2, we outline our theoretical model of how news media creates, reinforces, and changes the meta story of Bitcoin. News media makes interpretations of reality and publishes communicative events, such as news articles (b) to form five narratives. These narratives, through their internal interactions and within an institutional context, create the social reality (a) where actors form opinions and develop internal mental systems of the phenomenon. This, in turn, leads to actions that impact the exchange rate and triggers new communicative events (b). As the meta story develops and becomes part of the institutional context, it too reinforces (c) or might recreate the social reality (a). To complement Figure 2, we present Figure 3, which shows the relationship between Bitcoin exchange rate (the black line) against the cumulative emergence of new narratives. The meta story and its narratives reflect how news media interprets and portray Bitcoin with its actors and volatile exchange rate. We begin by discussing the five narratives followed by our meta story that emerged as part of the analysis.
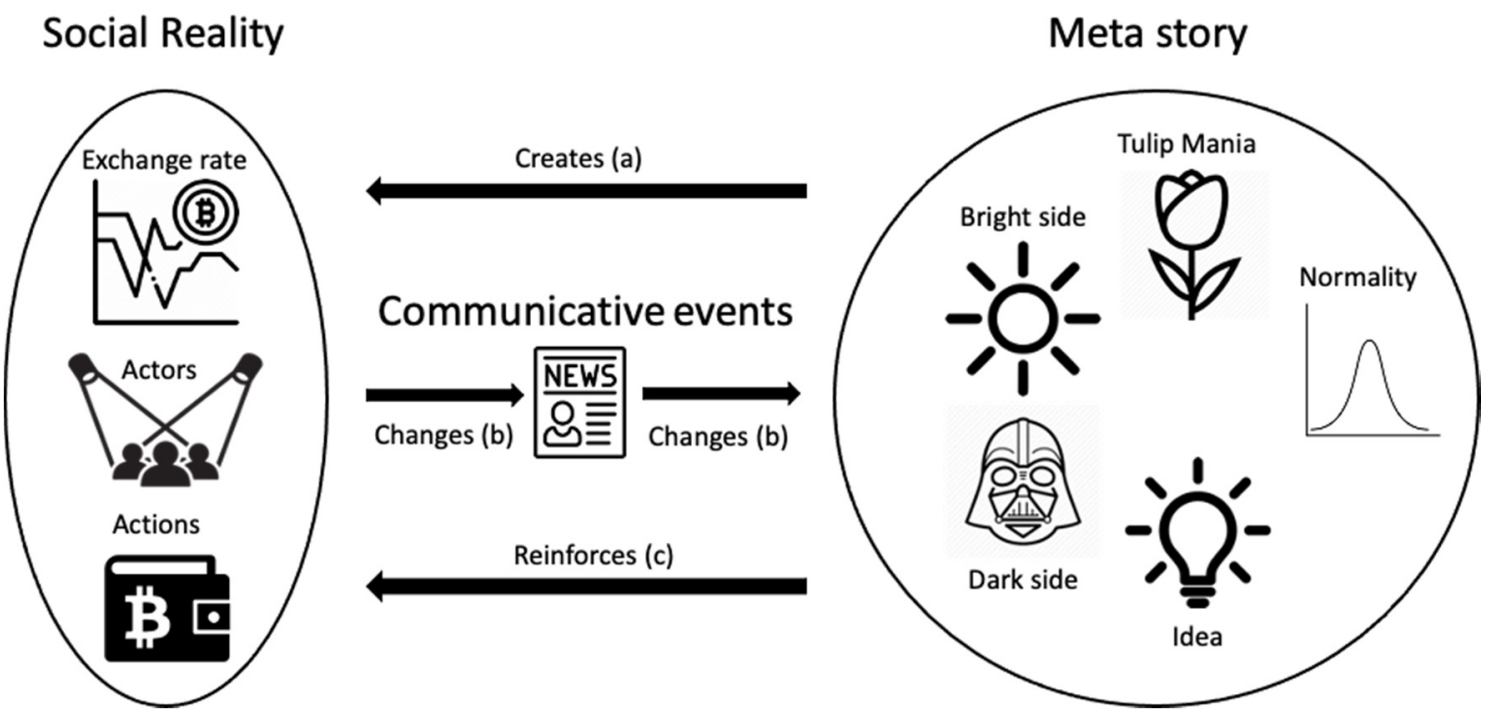

Figure 2. The Social Construction of Bitcoin in Media.

\subsection{Five Bitcoin Narratives}

\subsubsection{The Dark Side}

This narrative focuses on stories about how Bitcoin is being used for criminal activities like the drug trade, bribery, financing terrorism, buying child porn, and fake passports on the dark web. The narrative is an illustration of the negative aspects of information technology use-the dark side of IT [84-86]. In fact, it has been estimated that $46 \%$ of bitcoin transactions valued at roughly $\$ 76$ billion involves illegal activity [31]. This line of research 
diverges from research having a positive interpretation of information technology's impact on organizations and individuals by focusing on how information technology can be used with criminal intent. An example is found in the article "Virtual currencies valuable to criminals" [87]. Another article discussed how thousands of Swedish PC users have been hacked and infected by a trojan called Zeroaccess and how the SvD reports about "yet another" Bitcoin bank being robbed [88]. The Dark Side shows the digitalization of criminality, ranging from petty crime to systemic crime by countries.

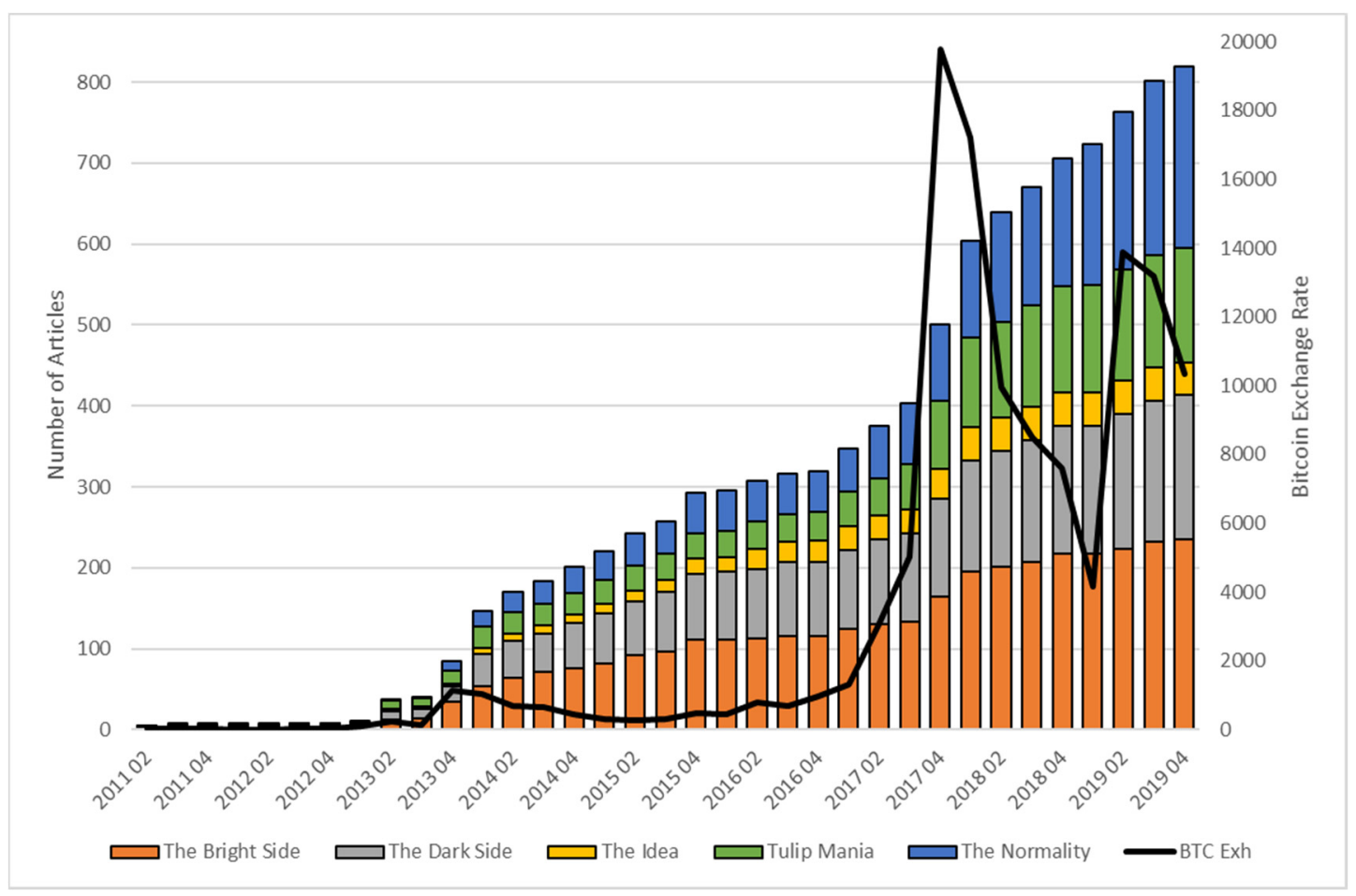

Figure 3. Bitcoin Exchange Rate and related Narratives during this timeframe.

\subsubsection{The Bright Side}

The Bright Side focuses on Bitcoin as an innovation and its potential to transform society. In that sense, it follows most early-stage innovation research focusing on the endless possibilities the technology offers [13]. This narrative is deterministic since it assumes that technology dictates our future direction [89], but also at the same it shows human faith in our ability to invent solutions to grand issues of our time. Thus, we find themes on how the Bitcoin ecosystem is growing and the increasing acceptance and interest from venture capitalists, policymakers, and the general public. The article "Bitcoin refuses to flip" is one illustration of this narrative. Bitcoin "has gradually gained acceptance as a digital currency that, unlike dollars or euros, can move through the global trade system with low fees, relative privacy, and no regulation", which in turn may lead to financial disruption. WP's review of the book, "Age of Cryptocurrency", reinforces the narrative by foretelling that Bitcoin will put pressure on the incumbents and others in adjacent fields to innovate [90]. Stressing the innovation aspect, there are articles about how Bitcoin is more than "just" a digital currency. The potential of the blockchain technology and applications outside using Bitcoin for trading goods or services fall into this category. One example where the reader is asked the rhetorical question what it would prefer: American Express, MasterCard, and Visa, who charge roughly 2 percent of every transaction, or another payment option that is for free. 


\subsubsection{The Tulip Mania}

The third narrative draws its name from the tulip bubble in the Netherlands in 1637, which is generally considered the first recorded speculative bubble [91]. Even in recent times we find support for speculative bubbles which tend to be driven by inexperienced investors. One example of this narrative was found in the article "The Bitcoin currency's progress is a failure for the euro". The article discusses Bitcoins virtual nature and describes how the value of the currency (at the time the article was published) has varied from a few cents up to 130 USD. The author states that "many compare it to the 1630s Holland, where the value of tulip bulbs without any rational explanation reached astronomical levels and then collapsed" [92]. This narrative not only highlights the extreme rises in the Bitcoin exchange rate but also the steep falls and declarations of a "death sentence". As one Swedish paper notes, "Bitcoin close to a technical collapse" [93]. Humans' ability to learn from history is limited [94], and the Tulip Mania narrative reflects this. We see humans herding nature emerge as the silver bullet to wealth is sought [95].

\subsubsection{The Normality}

The year 2019 marks the 10-year celebration of Satoshi's white paper, and a narrative of normality surrounding Bitcoin is prevalent. This narrative, which began to form early through brief mentions in news articles, picks up steam in 2017 and represents the legitimization of Bitcoin and its acceptance in culture and as a part of business. It shows how Bitcoin has become part of our everyday technological understanding [96]. In this narrative, we see the price of bitcoin quoted alongside the S\&P and NASDAQ, and regulations and legal issues continue to play a role in the legitimizing of Bitcoin as lawmakers and governments intervene. Even the activity level of illegal transactions compared to legal use of bitcoin takes a turn and steadily declines beginning in 2016 [31]. This narrative turns toward a discussion regarding how retail and commercial investors could invest and trade Bitcoins on stock exchanges. In this narrative, we also include articles that mention Bitcoin only briefly in a subordinate clause or with little explanation signaling that Bitcoin, as a concept, is understood by every reader. The addition of Bitcoin to the Scrabble dictionary brought forth wordplay such as "What cool/foolhardy people use for money". These narratives do not focus on speculation, criminal activities, or even the innovativeness of Bitcoin; instead, these narratives assume Bitcoin is part of the popular culture. Similar to what Abrahamson [97] labels as fad to fashion in the diffusion of innovation. New technologies do not disrupt, instead, particularly in socio-technical regimes that are heavily regulated, disruption takes time.

\subsubsection{The Idea}

There are several mysteries about Bitcoin that creates attention and discussion. One of them is about its creator Satoshi Nakamoto-a pseudo name representing an anonymous person or group and is one of the big mysteries that have steered ample speculation. Another recurring theme is how Bitcoin works and functions with a desire to inform society and people about the technology. In line with these stories are attempts to explain why there is a need for cryptocurrencies beyond the purpose of money. For instance, how Bitcoin can facilitate transactions that the traditional payment system does not want to deal with and thereby creates a sense of liberation, freedom, and self-sovereign control. In this vein, we see ideology being a part of the Bitcoin story, which brings in discussions of a cashless society, equality in banking systems, and libertarian viewpoints. Ideologies provide a deep structure [98] that allow sensemaking of innovations. For example, Bitcoin is described as a safe haven based on a libertarian undertone referring to Bitcoin as a currency free from politicized central banks, government supervision, and banks' high fees and transaction costs. This view is particularly relevant in cases of financial crisis; for instance, "Bitcoin value is soaring after the Cyprus crisis". Articles in this narrative often bring up Bitcoin's independence of central authority and decentralized nature as its most attractive feature [99]. 


\subsection{A Meta Story of Bitcoin as Told through the Media}

While Figure 3 represents the prevalence of the narratives graphically over time, our constructed meta story below provides added richness and depth. Given our constructivist approach, it is important to locate the narratives surrounding the Bitcoin in a historical context and how these narratives evolved temporally with key events and actors, and how Bitcoin has evolved and diffused in society. Table 2 presents the key historical events emerging from the discourse surrounding the emergence of Bitcoin that acted as a sensitizing device and sensemaking tool in creating our meta story.

Table 2. Key events in the history of Bitcoin.

\begin{tabular}{|c|c|}
\hline Year & Events \\
\hline 2008 & Global financial crisis \\
\hline 2008 & Publication of Satoshi's white paper \\
\hline 2011 & Time Magazine publishes the first article about Bitcoin \\
\hline 2013 & $\begin{array}{l}\text { FinCEN issues guidelines on the legal status of Bitcoin under the nation's } \\
\text { money laundering laws }\end{array}$ \\
\hline 2013 & The Cypriot financial crisis \\
\hline 2013 & US authorities seized assets from MtGox \\
\hline 2013 & $\begin{array}{l}\text { FBI shuts down the online black market Silk Road. However, Silk Road } 2.0 \text { is } \\
\text { up and running within a few weeks. }\end{array}$ \\
\hline 2013 & $\begin{array}{l}\text { The Chinese central bank announces that financial institutions are prohibited } \\
\text { from exchanging bitcoin }\end{array}$ \\
\hline 2014 & Overstock announces that they are accepting bitcoin \\
\hline 2014 & $\begin{array}{c}\text { The CEO of BitInstant is arrested and charged with engaging in a } \\
\text { money-laundering scheme }\end{array}$ \\
\hline 2014 & $\begin{array}{l}\text { MtGox, the world's largest trading platform for bitcoins at the time, files for } \\
\text { bankruptcy protection }\end{array}$ \\
\hline 2014 & FEC legalizes bitcoin contributions to political committees \\
\hline 2014 & New York State releases the first draft of BitLicense \\
\hline 2014 & Paypal announces that it allows its merchants to accept bitcoin payments \\
\hline 2015 & $\begin{array}{l}\text { Wall Street Journal reveals that the secretive startup } 21 \text { Inc had raised } \\
\qquad \$ 116 \mathrm{~m} \text { in funding }\end{array}$ \\
\hline 2015 & The "hard fork" Bitcoin XT is released \\
\hline 2016 & $\begin{array}{l}\text { Nine of the world's leading financial institutions announces their plans to } \\
\text { work on the blockchain in collaboration, forming a consortium led by the } \\
\text { startup R3 CEV }\end{array}$ \\
\hline 2016 & $\begin{array}{l}\text { Mike Hearn, one of bitcoin's lead developers, ends his involvement with } \\
\text { bitcoin and sells all of his remaining holdings because he believes the digital } \\
\text { currency has "failed". }\end{array}$ \\
\hline 2017 & The price broke US $\$ 2000$, reaching US $\$ 19,783$ by December \\
\hline 2017 & $\begin{array}{l}\text { Bitcoin cash launched after an internal dispute between owned of } \\
\text { large blocks. }\end{array}$ \\
\hline 2018 & $\begin{array}{l}\text { Bitcoin price was affected by several hacks or thefts from cryptocurrency } \\
\text { exchanges, including thefts from Coincheck. }\end{array}$ \\
\hline 2021 & Bitcoin becomes legal tender in El Salvador \\
\hline
\end{tabular}

4.2.1. The Calm before the Storm 2008-2012

The Bright Side of Bitcoin starts with "Imagining a world without the dollar" (Eichengreen 29 April 2011). The article illustrates the innovation and its power to transform payments 
and money. It builds upon the path set by Time Magazine in 2011, which describes Bitcoin as a "revolutionary concept", referring to the avoidance of artificial currency inflation, anonymity, and independence of third-party intermediaries for making transactions. Prior to this, Bitcoin was an unknown phenomenon for the general public, even though the first Bitcoin transaction took place, and the first Bitcoin exchange rate was established (US\$1 = 1309.03 BTC) in mid-January 2009. In parallel, The Dark Side emerges in SvD's first article: "Drugs may cause the fall of the new net currency" [100], which highlights the use of Bitcoin as a payment method in illegal markets.

\subsubsection{The Breakthrough 2013}

In 2013, the media interest grew. In part driven by events such as the Financial Crime Enforcement Network (FinCEN) in the U.S., that issued guidelines on the legal status of Bitcoin under the nation's money-laundering laws, thereby forcing Bitcoin exchanges to register as Money Services Businesses (MSBs) and comply with anti-money laundering regulations. Additionally, in 2013, the exchange rate began to increase dramatically, reaching US\$266 in April, but within a few weeks, the price fell back to US\$66. One explanation was the Cypriot financial crisis. In this context, The Tulip Mania saw its light. Later the same year, US authorities seized assets from MtGox, the world's largest Bitcoin trading platform, for illegally operating as a money transmitter. Subsequently, the FBI attempted to shut down the online black-market Silk Road. In the fall of 2013, the Chinese central bank announced that financial institutions were prohibited from exchanging Bitcoin. Creating only minor setbacks, and by the end of the year, the Bitcoin price surpassed US\$1000, bringing the total market capitalization to over US\$10 billion.

\subsubsection{The Scandals and Expansion of 2014}

When PayPal announced that it would allow its merchants to accept Bitcoin payments, and Overstock, a Nasdaq listed e-commerce site, announced that they were starting to accept Bitcoin, we see an illustration of the expansion of The Bright Side into "traditional" businesses. Overstock made 780 Bitcoin sales worth $\$ 127,000$ in the first $21 \mathrm{~h}$ after the announcement representing pent-up demand. In parallel, Bitcoin was slowly making its way onto different exchange marketplaces to be traded alongside traditional securities. The Dark Side is present as evidenced by events such as the CEO of the Bitcoin exchange startup BitInstant being arrested and charged with engaging in a money-laundering scheme and MtGox, the largest bitcoin exchange platform at the time, filed for bankruptcy. MtGox had reportedly lost 750,000 Bitcoins (around US\$412.5 million) belonging to customers and over 100,000 Bitcoins (around US\$55 million) of its own money. Despite these scandals, the Federal Election Commission in the U.S. legalized Bitcoin contributions to political committees, provided the amount is less than $\$ 100$. The Bitcoin price regained some value as it moved from below US\$400 to over US\$600. In July, New York State released the first draft of BitLicense, a plan to regulate Bitcoin and other cryptocurrencies. These regulations asked Bitcoin businesses to store not only the physical addresses of their customers but also the address of those who send their customers money using the Bitcoin network. These regulations received intense criticism for undermining the very idea of a decentralized open ledger, triggering articles shaping the narrative of The Idea.

\subsubsection{The Internal Battle 2015-2016}

There is an ongoing battle between the three narratives of The Dark, The Bright, and The Tulip Mania, illustrating the events around Bitcoin. At the beginning of 2015, the price moved between US\$200-300. Wall Street Journal revealed that the Bitcoin hardware start-up, $21 \mathrm{Inc}$, had raised $\$ 116 \mathrm{~m}$ in funding. This was the biggest funding round ever by a start-up in the digital-currency sector. Later that year, a group of developers made a new copy of Bitcoin's source code with some significant changes. This "hard fork" reflected an ongoing debate regarding the current $1 \mathrm{MB}$ block size limit, which restricts the network to a maximum capacity of seven transactions per second. Named Bitcoin XT, the fork, led by 
Mike Hearn, had come about because of frustration with the consensus-driven governance of Bitcoin Core (the current version of the Bitcoin software). Unlike Bitcoin Core, Bitcoin XT would not run on consensus but instead could be forked and modified by others.

The debt crisis in Greece took a turn for the worse when the country became the first ever to fail to repay a loan to the International Monetary Fund (IMF). During this time, Greek banks placed limits on cash withdrawals and money transfers creating fiat currency uncertainty not only within Greece but onlooking European citizens as well. Coindesk noted that "though little evidence was found that Greek buyers were behind Bitcoin's rising price, some commentators noted that the perception of the digital currency's utility as a hedge for the euro was convincing investors of its potential". Starting in August, Bitcoin experienced a price rally as the value moved from around US\$200 to US\$465 in December.

In 2016, a major setback in price occurred where Bitcoin declined by $10 \%$ in one day. The fall in price resulted when Mike Hearn, who recently had joined R3 CEV, said in a blog post that he was ending his involvement with Bitcoin and selling all of his remaining holdings because the digital currency had "failed". Nevertheless, during the fall, the exchange rate started to pick up, mainly due to Chinese activity at the end of the year, with the prices reaching US\$952.

\subsubsection{The Roller Coaster 2017-2021}

After a slight setback at the beginning of 2017, the price started to pick up again. In May, the price broke US \$2000. Part of the internal discord among the Bitcoin community in 2016 revolved around how the processing surrounding Bitcoin transactions could be scaled, especially given the current $1 \mathrm{MB}$ block size limit. Two solutions were put fortheither to verify a smaller amount of the block or to increase the block size limit, thereby increasing the number of transactions that could be validated at one time. In August 2017, a solution to verify a smaller portion of the block (the Segregated Witness or SegWit software upgrade) was approved and activated on the network. Immediately, the exchange rate rose $50 \%$ to $\$ 2748$. However, several owners of large blocks were dissatisfied with the SegWit and subsequently created Bitcoin Cash (a solution to increase the block size to $8 \mathrm{MB})$. Prices kept on rising to hit an all-time high on the 17 December at $\$ 19,783$. China had banned Bitcoin trading, which came into effect on 1 February 2018. Even before the Chinese ban, the exchange rate had plummeted below $\$ 10,000$, but the pace picks up, and in early February, the price was at \$6914. More importantly, the number of transactions fell by more than $30 \%$. The price continued to decline during most of the year, ending at $\$ 3747$. It was not only regulatory changes affecting the prices. Several cryptocurrencies were hacked during the year, including Coincheck, Coinrail, Bithumb, and Bancor, and more than $\$ 750$ million worth of cryptocurrencies was lost. In support of the price, in fall 2018, the Intercontinental Exchange (the owner of the NYSE) began trading in Bitcoin futures on its exchange called Bakkt. During this period of rising exchange rates, The Normality narrative became more prevalent, which illustrates how Bitcoin became part of a broader discourse and begins to act as a reference point for other cryptocurrencies and is acknowledged as legal tender in El Salvador in 2021. As Bitcoin becomes part of everyday culture, we see a decreasing emphasis on The Bright Side narrative, to be replaced by The Normality.

\section{Discussion}

In this study, we take a constructionist lens with an emphasis on how digital innovation is socially constructed [43] in and by media. Separately, the identified narratives, The Bright Side, The Dark Side, the Tulip Mania, The Idea, and The Normality, primarily convey information about the content, but collectively together with real events, they form a meta story through which we can see more clearly how these communicative events (i.e., the news articles) take part in the construction of reality. Distinguishing between an event, the media report, and the narrative frame allows an opening of the black box to understand how social reality is constructed [63]. The interaction between these elements 
creates a shared mental model that can sway populations toward particular views and, consequently, actions [101]. We thus view these narratives as products and creators of socially shared mental models that enable sensemaking and lead to action.

For example, the narrative, The Idea, is about the philosophical and ideological aspects of Bitcoin as envisioned by Nakamoto. When considering the broader economic context in 2008 when the economy was still reeling from the financial crisis, the idea of a monetary system that did not rely on central or commercial banks, and in fact, did not rely on any centralized authority was appealing to many. This alignment with an ideology that rejected a central authority facilitated the incorporation of the idea of Bitcoin into deep structures upon which impression, beliefs, and actions could then occur [98].

We also see evidence of social construction along other dimensions of our meta story. For example, much of The Bright Side narrative concentrates on the developing nature of the technology, as evidenced by the fluctuation in the number of articles published over time. We see within some time periods a persistent level of stories, with peaks running followed by a decline, pointing perhaps to the evolving nature of the Bitcoin as the narrative seeks to reinterpret and reinvent the uses and diffusion pattern of innovation. The narrative related to The Bright Side does not stay constant but evolves from focusing on who is using Bitcoin to how it is used.

The Dark Side narrative is also prevalent throughout. Its purpose is to provide a cautionary tale to balance the exuberance and positive outlook of The Bright Side narrative. The highest concentration of The Dark Side narrative was evident throughout 2014, but this was also counterbalanced by the highest number of The Bright Side narratives. This tension between bright and dark reflect a dialogic nature (as compared to a dialectic)-that is, conflicting and alternative interpretations of an innovation can coexist at the same time, and both have truth. This "fusion of scandal and miracle" and the paradoxes therein make for the bones of a great story [48] (p. 7).

Recognizing social actions and their impact on technology is key to understanding what aspects are privileged and given weight and which have little power. We see this in our meta story as The Dark Side narrative is a constant narrative throughout-yet it seems to have little influence on volatility, innovativeness, or on the move toward normality. The social structures prevalent within both the US and Sweden perhaps see The Dark Side as an unfortunate yet ever-present part of the social structure, but one that does not intrude within their own structures or practices. So, while investors recognize the use of Bitcoin in Dark Side activities, this does not preclude their personal legal use of Bitcoin.

Furthermore, toward the end of our study, we see yet more changes as The Bright Side narratives contracts overall, to be replaced by The Normality narrative. As actors become more comfortable with an innovation, the conception of the innovations moves from being a novelty to part of everyday life. The early adopters give way to the early majority (Rogers 2010), and, consequently, the narrative surrounding this shift must shift as well. The changes to the underlying code through the SegWit and Bitcoin Cash fork precipitated a steep rise in price, and this was accompanied by regulations that allowed public trading of Bitcoins, which increased the demand for Bitcoins. As the exchange rate was rising sharply, so too did the reports in media. Much of it related to the Tulip Mania, but during this period, we also see the narrative focusing on popular culture (The Normality), away from ideology (The Idea), and away from innovation (The Bright Side), and toward the acceptance of Bitcoin as an alternative investment available to retail investors. However, to the extent that Tulip Mania influences the volatility is uncertain, but clearly, the correlation between the number of articles and the exchange rate is persistent.

The Normality narrative also indicates we may be reaching a stabilization of the technology. In stabilization, the technology becomes less subject to interpretive flexibility and instead is treated more like a black box [102]. As this stage is reached, the uses, beliefs, and assumptions surrounding the innovation become less varied, and while we might still see narratives related to The Dark Side, it is less likely to have a negative influence as structures and beliefs deepen. During stabilization, we would also expect more stability in 
price as participants settle into predictable roles such as investor/trader, holder of value, or even criminal.

These differences in interpretations of the same technology can be accounted for by understanding that objects are more than their material aspects (i.e., more than an alphanumeric string) but also allow for interpretive flexibility [102]. This explains why the social aspect has a significant influence on the practices and uses of a material/unitary technology such as Bitcoin (i.e., instantiated using the same algorithm and same process globally). Ideologies thus provide a deep structure upon which competing discourses are framed [98]. It is through ideologies, which are essentially the abstract mental systems that organize socially shared attitudes and that indirectly influence the personal cognition of group members as they act as filters through which we see and interpret the world Van Dijk [103].

\section{Media's Role in Framing Digital Innovations}

Media's ability to shape public opinion has been suggested time and time again [6,7] and we see evidence of shifts in investor attention impact the price of bitcoin [104]. By promoting a particular narrative, angle, or frame, the media can "determine" how an issue is understood and thereby shift public opinion. For instance, Bitcoin has been referred to as "potentially disruptive" on several occasions. It can be assumed that it is used in a colloquial way, referring to Bitcoin's potential to dramatically change or disturb the current order of one or several industries. The fact that multiple cases of the theme "Financial disruption" were identified in this study reinforces this notion. Bitcoin has also been described as a "technological development of similar magnitude and potential" as the Internet [105]. However, media's role is complex as they "simultaneously may act as constructors of unique frames as well as a conduit for the public communiqués of others", as Callaghan and Schnell [106] phrases it. Although journalists have control over mass media narrative, it would be unfair to make them solely accountable. Thus, the power of shaping public opinion makes the media stories an interesting data source, especially since it reveals the institutional context of digital innovations.

\section{Implications}

Our study makes several contributions. First, we contribute to the understanding of how the institutional context influence actors framing process of digital innovations by outlining a model (see Figure 2) that depicts the role of how media shapes our reality. Previous work has highlighted the relationship of news media and stock market returns [5]; our study unpacks this relationship by way of a narrative analysis. We demonstrate how this iterative, ongoing process of interacting mental models and narratives [43] provides a complementary explanation of digital innovation diffusion that is multifaceted, particularly during their early phases [7]. Thus, the model shows how interweaved media is in our sensemaking of digital innovation and thereby complements other sensemaking models [50], such as power in sensemaking processes [107], technology features [108], or media at work [109]. In the future, we encourage work that aims to develop new sensemaking models, for instance of the role of social media in the construction of digital innovations.

Second, the five narratives, The Dark Side, The Bright Side, the Tulip Mania, The Idea, and The Normality, are a step towards theorizing of digital innovations. They provide an outside-in view that complements existing research on Bitcoin with its historical inside-out view $[13,110]$. Having this rich understanding is important in comprehending the more subtle aspects of digital innovations since the narratives provide a different light. This could move researchers' focus from the hype to reality. Furthermore, in our nearly ten years of data, we also reveal how and when narratives evolve, or new narratives emerge. From a micro perspective, we have a better understanding of how a single narrative influences the meta story. For example, we saw how the nature of The Bright Side evolved over time and the emergence of The Normality narrative as actors became more familiar with 
the innovation. This is important to owners, speculators, miners, and policymakers to be cognizant of the changing narratives and the implications on the meta story going forward.

Third, the meta story gives a broad longitudinal interpretation of Bitcoin and how it has matured. It is not a straightforward process; instead, it involves rapid expansions and drastic setbacks, yet all the while moving forward with investor attention and momentum playing a strong role [104]. Thus, it complements previous narrative studies on technology innovations, for instance, how media's depiction of a technology innovation (India's Aakash tablet) is representative of India's deeper cultural aspirations [111]. Additionally, Wang [112] and Wang and Ramiller [113] used this approach in analyzing media and public discourse to understand how the business community came to understand ERP systems as a new technology innovation.

Besides the theoretical implication, there are practical and policy implications as well. Given a current market capitalization of close to USD $\$ 900$ billion, understanding how Bitcoin came to be and what might influence its future, as told by the meta story is crucial to policymakers as they balance between regulation and anarchy with the goal to find a reasonable balance so as not to squelch this promising innovation. As the growth of fintech increasingly plays a vital role (e.g., shadow banks), we contribute to the ongoing understanding of how regulation and technology contribute to growth [114]. Practitioners need to remember that news media articles are not objective. The same event involving the same actors may lead to very different interpretations and stories. Individuals read the media stories, form impressions, and act based on their mental model formed and the telling of events [10]. Consequently, practitioners, managers, as well as policymakers need to reflect upon how narratives might influence their sensemaking. According to van Dijk, it is socio-cognition, "the system of mental representations and processes of group members", that mediates between society and discourse [103] (p. 18).

As with any research, ours is subject to limitations. The news articles provide ample basis for analyzing and identifying the narratives. However, the two newspapers do have some limitations in that they represent a limited view both in terms of geographic representation and ownership (i.e., we don't claim that these narratives are universal-they only represent the two newspapers). Other newspapers in Sweden, the US, or other parts of the world might provide differing or additional views. Such a limitation is in line with the fact that we did not aim at providing generalizable findings applicable to other empirical settings, but instead, in the tradition of many qualitative studies, we aim to generalize toward theory [72].

\section{Conclusions}

Bitcoin is one of the many digital innovations that has entered the scene. As a developing story, our purpose is to shed light on how digital innovations were portrayed in the news media and how this shaped the general perception of the innovation. Media is not objective; on the contrary, it is subjectively shaped by its own context, which in turn shapes our understanding of digital innovations. The five narratives identified are illustrations of the socially constructed nature of digital innovation. In the study, it was found that the movement of Bitcoin's exchange rate, events that are directly or indirectly related to Bitcoin, as well as the evolving narrative have been strong driving forces affecting how the story has developed over time. It is clear that the price volatility is correlated with both media activity and the general narrative trends. When the price goes up, so does the media activity-usually following a period dominated by a progressive theme like "The Rise of Bitcoin". On the other side, when the price drops, conservative and skeptical Tulip Mania and The Dark Side narratives focusing on speculation and shady business become more prominent. However, over time, Bitcoin, as do other potentially digital innovations, becomes part of everyday business as it reaches normality - and as such, transforms from innovation to becoming a reference point for new technology innovations.

This study stands in the line of research pointing at the opinion-shaping power of the media. "If the text frame emphasizes a variety of mutually reinforcing ways that the 
glass is half full, the evidence of social science suggests that relatively few in the audience will conclude it is half empty", as Entman [115] eloquently phrases it. By shaping public opinion, the media is also shaping the world. Therefore, media's polarization of Bitcoin should be taken seriously. Whether Bitcoin is presented in the news as a facilitator of the drug trade, or a disruptor of the financial industry it could play a significant part in the resultant actions of actors and the fate of the technology that has the potential to change our conceptual understanding of trade, ownership, and trust.

Author Contributions: Conceptualization, J.H., T.B. and M.K.; Data curation, M.K., J.H. and T.B.; Formal analysis, M.K., J.H. and T.B.; Methodology, M.K. and T.B.; Writing-original draft, M.K. and J.H.; Writing-review \& editing, J.H. and T.B. All authors have read and agreed to the published version of the manuscript.

Funding: This research received no external funding.

Institutional Review Board Statement: Not applicable.

Informed Consent Statement: Not applicable.

Data Availability Statement: Not applicable.

Acknowledgments: This work was supported by the Nordic Finance and the Good Society project at Center for Corporate Governance and the Department of Digitalization, Copenhagen Business School, Denmark and Maine Business School, University of Maine, USA. Authors are thankful for the support.

Conflicts of Interest: The authors declare no conflict of interest. Similarly, the supporters had no role in the design of the study; in the collection, analyses, or interpretation of data; in the writing of the manuscript, or in the decision to publish the results.

\section{Appendix A}

Table A1. Narratives, Theme, and Open Codes.

\begin{tabular}{|c|c|c|c|}
\hline Narrative * & Theme * & Open Code & Count \\
\hline \multirow{18}{*}{ The Bright Side (235) } & \multirow{5}{*}{ Adoption (49) } & Acceptance & 24 \\
\hline & & Adoption & 3 \\
\hline & & Adoption: Merchant & 23 \\
\hline & & Adoption: Risk & 1 \\
\hline & & Diffusion & 1 \\
\hline & \multirow{2}{*}{ Alternate Currencies (15) } & Alternate Currency & 8 \\
\hline & & New Kind of Currency & 7 \\
\hline & \multirow{6}{*}{ Bitcoin Ecosystem (44) } & Auction & 4 \\
\hline & & Ecosystem & 27 \\
\hline & & Evolution & 1 \\
\hline & & Crypto Evolution & 1 \\
\hline & & Macroeconomics & 10 \\
\hline & & Supply & 1 \\
\hline & \multirow{3}{*}{ Entrepreneurship (5) } & Entrepreneurship & 1 \\
\hline & & Entrepreneurship: Crowdfunding & 2 \\
\hline & & Entrepreneurship: Initial Coin Offerings (ICO) & 2 \\
\hline & \multirow{2}{*}{ Financial Disruption (23) } & Banks' Reaction & 10 \\
\hline & & Disruption & 13 \\
\hline
\end{tabular}


Table A1. Cont.

\begin{tabular}{|c|c|c|c|}
\hline Narrative * & Theme * & Open Code & Count \\
\hline & \multirow{3}{*}{ Innovation (12) } & Blockchain & 10 \\
\hline & & Innovation & 1 \\
\hline & & Technology & 1 \\
\hline & \multirow{8}{*}{ Investment (46) } & Art & 1 \\
\hline & & Bitcoin Millionaires & 5 \\
\hline & & Hedge & 1 \\
\hline & & Investment & 18 \\
\hline & & Trade & 12 \\
\hline & & Trading & 8 \\
\hline & & VC Investment & 1 \\
\hline & & Wealth & 1 \\
\hline & \multirow{8}{*}{ Mechanics (18) } & Algorithm & 1 \\
\hline & & Anonymity & 1 \\
\hline & & Anonymous & 2 \\
\hline & & Applications & 5 \\
\hline & & Control & 1 \\
\hline & & How It Works & 6 \\
\hline & & How To & 1 \\
\hline & & Transaction Fees & 1 \\
\hline & Political (3) & Political & 3 \\
\hline & \multirow{5}{*}{ Production (12) } & Energy & 1 \\
\hline & & Miners & 1 \\
\hline & & Production & 4 \\
\hline & & Production Mining & 1 \\
\hline & & Production: Energy & 5 \\
\hline & \multirow{6}{*}{ Regulatory Issues (46) } & China Regulation & 1 \\
\hline & & China Work Arounds & 2 \\
\hline & & Regulation & 11 \\
\hline & & Regulation (Licensing) & 1 \\
\hline & & Regulatory & 5 \\
\hline & & Regulatory Issues & 26 \\
\hline \multirow{6}{*}{ The Dark Side (178) } & \multirow{2}{*}{ Fraud (5) } & Exchange: Hacked & 1 \\
\hline & & Fraud & 4 \\
\hline & \multirow{4}{*}{ Illegal Activity (135) } & Illegal Activity & 121 \\
\hline & & Illegal Activity: Money Laundering & 5 \\
\hline & & Illegal activity: Ransomware & 9 \\
\hline & & Illegal activity: Uncertainty & 1 \\
\hline
\end{tabular}


Table A1. Cont.

\begin{tabular}{|c|c|c|c|}
\hline Narrative * & Theme * & Open Code & Count \\
\hline & \multirow{4}{*}{ Risk (11) } & Risky & 8 \\
\hline & & Risk: Investment & 1 \\
\hline & & Risk: Not Currency & 1 \\
\hline & & Risk: Zero Value & 1 \\
\hline & \multirow{2}{*}{ Security (36) } & Security & 35 \\
\hline & & Theft & 1 \\
\hline & \multirow{2}{*}{ War/Terrorism (3) } & Terrorism & 1 \\
\hline & & War & 2 \\
\hline \multirow{9}{*}{ The Idea (41) } & \multirow{8}{*}{ Ideology (27) } & Alt-right & 2 \\
\hline & & Cashless Society & 3 \\
\hline & & Discussion & 1 \\
\hline & & Equality & 1 \\
\hline & & Financial Inclusion & 2 \\
\hline & & Idea & 4 \\
\hline & & Libertarian & 13 \\
\hline & & Societal issues & 1 \\
\hline & Satoshi (14) & Satoshi & 14 \\
\hline \multirow{17}{*}{ Normality (224) } & \multirow{13}{*}{ Brief Mention (218) } & Subordinate clause & 106 \\
\hline & & Business News & 1 \\
\hline & & Common Usage & 37 \\
\hline & & Comparison with Currencies & 3 \\
\hline & & Comparison with other Cryptocurrencies & 13 \\
\hline & & Police Blotter & 2 \\
\hline & & Popular Culture & 35 \\
\hline & & Price Quote & 6 \\
\hline & & Regulation & 2 \\
\hline & & Satoshi & 2 \\
\hline & & Taxation & 3 \\
\hline & & Trading on Exchanges & 6 \\
\hline & & Trends & 2 \\
\hline & \multirow{3}{*}{ Legal (5) } & China Bitcoin Exchange Stopped & 1 \\
\hline & & Confiscation & 2 \\
\hline & & Taxation & 2 \\
\hline & Employment (1) & Salary & 1 \\
\hline \multirow{5}{*}{ Tulip Mania (149) } & \multirow{2}{*}{ Bubble (8) } & Bubble & 7 \\
\hline & & Speculation & 1 \\
\hline & Death Sentence (4) & Death Sentence & 4 \\
\hline & \multirow{2}{*}{ Volatility (137) } & Crash & 1 \\
\hline & & Volatility & 136 \\
\hline
\end{tabular}

* Number in brackets indicate frequency of codes included. 


\section{References}

1. Nakamoto, S. Bitcoin: A peer-to-peer electronic cash system. Decentralized Bus. Rev. 2008, 21260. Available online: File:///C: /Users/MDPI/Downloads/21260-bitcoin-a-peer-to-peer-electronic-cash-system\%20(1).pdf (accessed on 5 October 2021).

2. Robinson, E.; Leising, M. Blythe Masters Tells Banks the Blockchain Changes Everything. Bloom. Mark. 2015. Available online: https:/ / www.bloomberg.com/news/features/2015-09-01/blythe-masters-tells-banks-the-blockchain-changes-everything (accessed on 5 October 2021).

3. Kearns, J. Greenspan Says Bitcoin a Bubble without Intrinsic Currency Value; Bloomberg: New York, NY, USA, 2013.

4. Clinch, M. Roubini Launches Stinging Attack on Bitcoin; CNBC: Englewood Cliffs, NJ, USA, 2014; Available online: http:/ /www. cnbc.com/2014/03/10/nches-stinging-attack-on-bitcoin.html (accessed on 5 October 2021).

5. Calomiris, C.W.; Mamaysky, H. How news and its context drive risk and returns around the world. J. Financ. Econ. 2019, 133, 299-336. [CrossRef]

6. Grossberg, L.; Wartella, E.; Whitney, D.; Wise, J. Mediamaking: Mass Media in a Popular Culture; Sage Publications: Thousand Oaks, CA, USA, 2006.

7. Hargadon, A.B.; Douglas, Y. When Innovations Meet Institutions: Edison and the Design of the Electric Light. Adm. Sci. Q. 2001, 46, 476-501. [CrossRef]

8. Kaplan, S.; Tripsas, M. Thinking about technology: Applying a cognitive lens to technical change. Res. Policy 2008, 37, 790-805. [CrossRef]

9. Agarwal, R.; Prasad, J. The antecedents and consequents of user perceptions in information technology adoption. Decis. Support Syst. 1998, 22, 15-29. [CrossRef]

10. Munir, K.A.; Phillips, N. The Birth of the 'Kodak Moment': Institutional Entrepreneurship and the Adoption of New Technologies. Organ. Stud. 2005, 26, 1665-1687. [CrossRef]

11. Goffman, E. Frame Analysis: An Essay on the Organization of Experience; Harvard University Press: Cambridge, MA, USA, 1974.

12. Orlikowski, W.J.; Gash, D.C. Technological frames: Making sense of information technology in organizations. ACM Trans. Inf. Syst. (TOIS) 1994, 12, 174-207. [CrossRef]

13. Swanson, E.B.; Ramiller, N.C. The Organizing Vision in Information Systems Innovation. Organ. Sci. 1997, 8, 458-474. [CrossRef]

14. Milian, E.Z.; de Spinola, M.; de Carvalho, M.M. Fintechs: A literature review and research agenda. Electron. Commer. Res. Appl. 2019, 34, 100833. [CrossRef]

15. Su, C.-W.; Qin, M.; Tao, R.; Umar, M. Financial implications of fourth industrial revolution: Can bitcoin improve prospects of energy investment? Technol. Forecast. Soc. Chang. 2020, 158, 120178. [CrossRef]

16. Bao, Z.; Shi, W.; Kumari, S.; Kong, Z.; Chen, C. Lockmix: A secure and privacy-preserving mix service for Bitcoin anonymity. Int. J. Inf. Secur. 2020, 19, 311-321. [CrossRef]

17. Reid, F.; Harrigan, M. An Analysis of Anonymity in the Bitcoin System; Springer: New York, NY, USA, 2013; pp. 197-223. [CrossRef]

18. Sarker, S.; Henningsson, S.; Jensen, T.; Hedman, J. The Use of Blockchain as A Resource for Combating Corruption in Global Shipping: An Interpretive Case Study. J. Manag. Inf. Syst. 2021, 38, 338-373. [CrossRef]

19. Eyal, I.; Sirer, E.G. Majority is not enough: Bitcoin mining is vulnerable. In Proceedings of the International Conference on Financial Cryptography and Data Security, Bridgetown, Barbados, 3-7 March 2014.

20. Bos, J.W.; Halderman, J.A.; Heninger, N.; Moore, J.; Naehrig, M.; Wustrow, E. Elliptic curve cryptography in practice. In Proceedings of the International Conference on Financial Cryptography and Data Security, Christ Church, Barbados, 3-7 March 2014.

21. Abramova, S.; Böhme, R. Perceived Benefit and Risk as Multidimensional Determinants of Bitcoin Use: A Quantitative Exploratory Study. In Proceedings of the 37th International Conference on Information Systems, Dublin, Ireland, 11-14 December 2016. [CrossRef]

22. Chipere, M. Virtual currency as an inclusive monetary innovation for the unbanked poor. Electron. Commer. Res. Appl. 2018, 28, 37-43. [CrossRef]

23. Mikhaylov, A. Development of Friedrich von Hayek's theory of private money and economic implications for digital currencies. Terra Econ. 2021, 19, 53-62. [CrossRef]

24. Schilling, L.; Uhlig, H. Some simple Bitcoin economics. J. Monet. Econ. 2019, 106, 16-26. [CrossRef]

25. Qin, M.; Su, C.; Tao, R. BitCoin: A new basket for eggs? Econ. Model. 2021, 94, 896-907. [CrossRef]

26. Schuetz, S.; Venkatesh, V. Blockchain, adoption, and financial inclusion in India: Research opportunities. Int. J. Inf. Manag. 2019, 52, 101936. [CrossRef]

27. Dyhrberg, A.H. Bitcoin, gold and the dollar-A GARCH volatility analysis. Financ. Res. Lett. 2016, 16, 85-92. [CrossRef]

28. Kazan, E.; Damsgaard, J. Towards a Market Entry Framework for Digital Payment Platforms. Commun. Assoc. Inf. Syst. 2016, 38, 761-783. [CrossRef]

29. Walsh, C.; Reilly, P.O.; Gleasure, R.; Feller, J.; Li, S.; Cristoforo, J. New kid on the block: A strategic archetypes approach to understanding the Blockchain. In Proceedings of the International Conference on Information Systems, Dublin, Ireland, 11-14 December 2016.

30. Baur, D.G.; Hong, K.; Lee, A.D. Bitcoin: Medium of exchange or speculative assets? J. Int. Financ. Mark. Inst. Money 2018, 54, 177-189. [CrossRef]

31. Foley, S.; Karlsen, J.R.; Putnins, T. Sex, Drugs, and Bitcoin: How Much Illegal Activity Is Financed through Cryptocurrencies? Rev. Financ. Stud. 2019, 32, 1798-1853. [CrossRef] 
32. Sun Yin, H.H.; Langenheldt, K.; Harlev, M.; Mukkamala, R.R.; Vatrapu, R. Regulating Cryptocurrencies: A Supervised Machine Learning Approach to De-Anonymizing the Bitcoin Blockchain. J. Manag. Inf. Syst. 2019, 36, 37-73. [CrossRef]

33. Baldwin, J. In digital we trust: Bitcoin discourse, digital currencies, and decentralized network fetishism. Palgrave Commun. 2018, 4,1-10. [CrossRef]

34. Conti, M.; Kumar, E.S.; Lal, C.; Ruj, S. A survey on security and privacy issues of bitcoin. IEEE Commun. Surv. Tutor. 2018, 20, 3416-3452. [CrossRef]

35. Hawlitschek, F.; Notheisen, B.; Teubner, T. The limits of trust-free systems: A literature review on blockchain technology and trust in the sharing economy. Electron. Commer. Res. Appl. 2018, 29, 50-63. [CrossRef]

36. Dood, N. The social life of Bitcoin. Theory Cult. Soc. 2018, 35, 35-56. [CrossRef]

37. Brito, J.; Castillo, A. Bitcoin: A Primer for Policymakers; Mercatus Center, George Mason University: Fairfax, VA, USA, 2013.

38. Yoo, K.; Bae, K.; Park, E.; Yang, T. Understanding the diffusion and adoption of Bitcoin transaction services: The integrated approach. Telemat. Inform. 2020, 53, 101302. [CrossRef]

39. Urquhart, A. The inefficiency of Bitcoin. Econ. Lett. 2016, 148, 80-82. [CrossRef]

40. Wang, J.; Wang, X. COVID-19 and financial market efficiency: Evidence from an entropy-based analysis. Financ. Res. Lett. 2021, 42, 101888. [CrossRef]

41. Hedman, J.; Gimpel, G. The adoption of hyped technologies: A qualitative study. Inf. Technol. Manag. 2010, 11, 161-175. [CrossRef]

42. Cukier, W.; Ngwenyama, O.; Bauer, R.; Middleton, C. A critical analysis of media discourse on information technology: Preliminary results of a proposed method for critical discourse analysis. Inf. Syst. J. 2009, 19, 175-196. [CrossRef]

43. Berger, P.L.; Luckmann, T. The Social Construction of Reality. A Treatise in the Sociology of Knowledge; Penguin Books Ltd.: London, UK, 1968.

44. Ramiller, N.; Pentland, B. Management Implications in Information Systems Research: The Untold Story. J. Assoc. Inf. Syst. 2009, 10, 474-494. [CrossRef]

45. Riessman, C.K. Narrative Analysis; Sage: London, UK, 1993; Volume 30.

46. Chouliaraki, L.; Fairclough, N. Discourse in Late Modernity; Edinburgh University Press: Edinburgh, UK, 1999.

47. Czarniawska, B. On time, space, and action nets. Organization 2004, 11, 773-791. [CrossRef]

48. Bruner, J.S. Actual Minds, Possible Worlds; Harvard University Press: Harvard, UK, 2009.

49. Webster, L.; Mertova, P. Using Narrative Inquiry as a Research Method: An Introduction to Using Critical Event Narrative Analysis in Research on Learning and Teaching; Routledge: London, UK, 2007.

50. Weick, K.E. Sensemaking in Organizations; Sage Publications: Thousand Oaks, CA, USA, 1995.

51. Garud, R.; Giuliani, A.P. A Narrative Perspective on Entrepreneurial Opportunities. Acad. Manag. Rev. 2013, 38, 157-160. [CrossRef]

52. Sarker, S.; Xiao, X.; Beaulieu, T.; Lee, A.S. Learning from First-Generation Qualitative Approaches in the IS Discipline: An Evolutionary View and Some Implications for Authors and Evaluators (Part 2/2). J. Assoc. Inf. Syst. 2018, 19, 909-923.

53. Bruner, J.S. Acts of Meaning; Harvard University Press: Cambridge, MA, USA, 1990; Volume 3.

54. Boland, R.J.; Schultze, U. Narrating accountability: Cognition and the production of the accountable self. In Accountability. Power, Ethos and the Technologies of Managing; Munro, R., Mouritsen, J., Eds.; Thompson Business Press: London, UK, 1996 ; pp. 62-81.

55. Czarniawska, B.A. Narrative Approach to Organization Studies; Sage Publications: Thousand Oaks, CA, USA, 1997.

56. Wagner, E.L.; Kandathil, G.M. Narrative Methodologies in Information Systems Literature: Illuminating Interconnectivity and Change over Time. Commun. Assoc. Inf. Syst. 2016, 39, 19. [CrossRef]

57. Hedman, J.; Bødker, M.; Gimpel, G.; Damsgaard, J. Translating evolving technology use into user stories: Technology life narratives of consumer technology use. Inf. Syst. J. 2019, 29, 1178-1200. [CrossRef]

58. Hoefnagel, R.; Oerlemans, L.; Goedee, J. How anchoring and adjusting influence citizens' acceptance of video-mediated crime reporting: A narrative approach. J. Strateg. Inf. Syst. 2014, 23, 305-322. [CrossRef]

59. Swap, W.; Leonard, D.; Shields, M.; Abrams, L. Using Mentoring and Storytelling to Transfer Knowledge in the Workplace. J. Manag. Inf. Syst. 2001, 18, 95-114. [CrossRef]

60. Wende, E.; King, G.; Schwabe, G. Exploring Storytelling as a Knowledge Transfer Technique in Offshore Outsourcing. In Proceedings of the International Conference on Information Systems, Auckland, New Zealand, 14-17 December 2014.

61. Dubé, L.; Robey, D. Software stories: Three cultural perspectives on the organizational practices of software development. Account. Manag. Inf. Technol. 1999, 9, 223-259. [CrossRef]

62. Alvarez, R.; Urla, J. Tell me a good story: Using narrative analysis to examine in-formation requirements interviews during an ERP implementation. ACM SIGMIS Database 2002, 33, 38-52. [CrossRef]

63. Wende, E.; King, G. Exploring Storytelling for Relationship Building in Offshore Outsourced Projects: An Action Research Investigation. In Proceedings of the 48th Hawaii International Conference on System Sciences (HICSS), Honolulu, HI, USA, 5-8 January 2015.

64. Van Gorp, B. The constructionist approach to framing: Bringing culture back in. J. Commun. 2007, 57, 60-78.

65. Crotty, M. The Foundations of Social Research: Meaning and Perspective in the Research Process; Routledge: London, UK, 1998.

66. Klein, H.K.; Myers, M. A Set of Principles for Conducting and Evaluating Interpretive Field Studies in Information Systems. Manag. Inf. Syst. 1999, 23, 67-94. [CrossRef] 
67. Morse, J.M. Perfectly Healthy, but Dead: The Myth of Inter-Rater Reliability. Qual. Health Res. 1997, 7, 445-447. [CrossRef]

68. Saldaña, J. The Coding Manual for Qualitative Researchers; Sage: London, UK, 2015.

69. Berente, N.; Hansen, S. Arguing the Value of Virtual Worlds: Patterns of Discursive Sensemaking of an Innovative Technology. Manag. Inf. Syst. Q. 2011, 35, 685-709. [CrossRef]

70. Walsham, G. Interpretive case studies in IS research: Nature and method. Eur. J. Inf. Syst. 1995, 4, 74-81. [CrossRef]

71. Edberg, D.; Ivanova, P.; Kuechler, W. Methodology Mashups: An Exploration of Processes Used to Maintain Software. J. Manag. Inf. Syst. 2012, 28, 271-304. [CrossRef]

72. Lee, A.S.; Baskerville, R.L. Generalizing Generalizability in Information Systems Research. Inf. Syst. Res. 2003, 14, 221-243. [CrossRef]

73. Gadamer, H.-G. The historicity of understanding. In Critical Sociology, Selected Readings; Connerton, P., Ed.; Penguin Books Ltd.: Harmondsworth, UK, 1976; pp. 117-133.

74. Phillips, H.; Hardy, C. Discourse Analysis: Investigating Processes of Social Construction; Sage Publications: London, UK, 2002; Volume 50.

75. Boland, R.J. Information system use as a hermeneutic process. In Information Systems Research: Contemporary Approaches and Emergent Traditions; Nissen, H.-E., Klein, H.K., Hirschheim, R.A., Eds.; North-Holland: Amsterdam, The Netherlands, 1991; pp. 439-464.

76. Ricoeur, P. Narrative identity. Philos. Today 1991, 35, 73-81. [CrossRef]

77. Clark, H.H.; Brennan, S.E. Grounding in communication. In Socially Shared Cognition; Resnick, L.B., Levine, J.M., Behrend, S.D., Eds.; American Psychological Association: Washington, DC, USA, 1991.

78. Eisenhardt, K.M. Building theories from case study research. Acad. Manag. Rev. 1989, 14, 532-550. [CrossRef]

79. Boeije, H. A Purposeful Approach to the Constant Comparative Method in the Analysis of Qualitative Interviews. Qual. Quant. 2002, 36, 391-409. [CrossRef]

80. McQuail, D. Media Performance: Mass Communication and the Public Interest; Sage: London, UK, 1992.

81. Janks, H. Critical discourse analysis as a research tool. Discourse Stud. Cult. Politics Educ. 1997, 18, 329-342. [CrossRef]

82. Hardy, C. Researching organizational discourse. Int. Stud. Manag. Organ. 2001, 31, 25-47. [CrossRef]

83. Langley, A. Strategies for theorizing from process data. Acad. Manag. Rev. 1999, 24, 691-710. [CrossRef]

84. Bohannon, J. Why criminals can't hide behind Bitcoin. Sci. Mag. 2016. [CrossRef]

85. Tarafdar, M.; Gupta, A.; Turel, O. The dark side of information technology use. Inf. Syst. J. 2013, 23, 269-275. [CrossRef]

86. Tarafdar, M.; Gupta, A.; Turel, O. Special issue on 'dark side of information technology use': An introduction and a framework for research. Inf. Syst. J. 2015, 25, 161-170. [CrossRef]

87. Erlandsson, A. Virtuella Valutor Värdefulla för Kriminella; Svenska Dagbladet: Stockholm, Sweden, 2013.

88. AFP; Reuters, T.T. Ännu en Bitcoin-Bank Rånad; Svenska Dagbladet: Stockholm, Sweden, 2014.

89. Ceruzzi, P.E. Moore's law and technological determinism: Reflections on the history of technology. Technol. Cult. 2005, 46, 584-593. [CrossRef]

90. Gross, D. Review: 'Age of Cryptocurrency', Bitcoin and Economy; Vigna, P., Casey, M., Eds.; The Washington Post: Washington, DC, USA, 2015.

91. Garber, P.M. Famous First Bubbles: The Fundamentals of Early Manias; MIT Press: Cambridge, MA, USA, 2001.

92. Sigfrid, K. Bitcoin-Valutans Framfart är ett Misslyckande för Euron; Svenska Dagbladet: Stockholm, Sweden, 2013.

93. Boyd, R.; Richerson, P.J.; Henrich, J. The cultural niche: Why social learning is essential for human adaptation. Proc. Natl. Acad. Sci. USA 2011, 108 (Suppl. 2), 10918-10925. [CrossRef]

94. Tuvhag, E. Bitcoin Nära en Teknisk Kollaps; Svenska Dagbladet: Stockholm, Sweden, 2016.

95. Prechter, R.R., Jr. Unconscious herding behavior as the psychological basis of financial market trends and patterns. J. Psychol. Financ. Mark. 2001, 2, 120-125. [CrossRef]

96. Yoo, Y. Computing in everyday life: A call for research on experiential computing. Manag. Inf. Syst. Q. 2010, 34, 213-231. [CrossRef]

97. Abrahamson, E. Managerial fads and fashions: The diffusion and rejection of innovations. Acad. Manag. Rev. 1991, 16, 586-612. [CrossRef]

98. Barrett, M.; Heracleous, L.; Walsham, G. A Rhetorical Approach to IT Diffusion: Reconceptualizing the Ideology-Framing Relationship in Computerization Movements. Manag. Inf. Syst. Q. 2013, 37, 201-220. [CrossRef]

99. Eriksson, K.A. Bitcoin-Värdet Rusar efter Cypernkrisen; Svenska Dagbladet: Stockholm, Sweden, 2013.

100. Tidningarnas Telegrambyrå. Droger Kan bli ny Närvalutas Fall; Svenska Dagbladet: Stockholm, Sweden, 2011.

101. Boje, D.M. The Storytelling Organization: A Study of Story Performance in an Office- Supply Firm. Adm. Sci. Q. 1991, 36, 106-126. [CrossRef]

102. Pinch, T.J.; Bijker, W. The Social Construction of Facts and Artefacts: Or How the Sociology of Science and the Sociology of Technology might Benefit Each Other. Soc. Stud. Sci. 1984, 14, 399-441. [CrossRef]

103. Van Dijk, T.A. Discourse analysis as ideology analysis. Lang. Peace 1995, 10, 47-142.

104. Liu, Y.; Tsyvinski, A. Risks and returns of cryptocurrency. Rev. Financ. Stud. 2021, 34, 2689-2727. [CrossRef]

105. Folkinshteyn, D.; Mark, M.L.; Timothy, R. A tale of twin tech: Bitcoin and the WWW. J. Strateg. Int. Stud. Forthcom. 2015, X, 82-90. 
106. Callaghan, K.; Schnell, F. Assessing the democratic debate: How the news media frame elite policy discourse. Political Commun. 2001, 18, 183-213.

107. Schildt, H.; Mantere, S.; Cornelissen, J. Power in sensemaking processes. Organ. Stud. 2020, 41, 241-265. [CrossRef]

108. Griffith, T.L. Technology features as triggers for sensemaking. Acad. Manag. Rev. 1999, 24, 472-488. [CrossRef]

109. Gephart, R.P., Jr. Sensemaking and new media at work. Am. Behav. Sci. 2004, 48, 479-495. [CrossRef]

110. Ramiller, N.; Swanson, E.B. Organizing visions for information technology and the in-formation systems executive response. J. Manag. Inf. Syst. 2003, 20, 13-50.

111. Mudliar, P.; Pal, J. ICTD in the Popular Press: Media Discourse around Aakash, the "World's Cheapest Tablet". Inf. Technol. Int. Dev. 2015, 11, 41-55.

112. Wang, P. Popular concepts beyond organizations: Exploring new dimensions of information technology innovations. J. Assoc. Inf. Syst. 2009, 10, 1-30. [CrossRef]

113. Wang, P.; Ramiller, N.C. Community learning in information technology innovation. Manag. Inf. Syst. Q. 2009, 33, 709-734. [CrossRef]

114. Vivek, W. How Apple's Trojan Horse will Eat the Credit Card Industry; The Washington Post: Washington, DC, USA, 2015.

115. Entman, R.M. Framing: Toward Clarification of a Fractured Paradigm. J. Commun. 1993, 43, 51-58. [CrossRef] 